\title{
Reflexões acerca da questão dos resíduos sólidos em territórios indígenas
}

\section{Lucas Braga da Silva ${ }^{1}$ e Édi Augusto Benini ${ }^{2}$}

\author{
${ }^{1}$ Faculdade São Marcos. Curso de Graduação em Administração. Rua Cuiabá, 1982, \\ Quadra 34, Lote 5 e 6. Vila Nova. Porto Nacional-TO (CEP 77500-000). E-mail: \\ lucaslogistica19@gmail.com. \\ ${ }^{2}$ Universidade Federal do Tocantins. Curso de Graduação em Administração. Bala \\ II, Sala 15. Avenida NS-15, ALCNO-14. Quadra 109 Norte. Plano Diretor Norte. \\ Palmas-TO, Brasil (CEP 77001-090).
}

Resumo. A Política Nacional de Resíduos Sólidos apresenta o respeito às diversidades locais e regionais como um de seus princípios norteadores para a gestão integrada por todo o território brasileiro. Aponta ainda a elaboração de planos de gestão integrada como instrumento para a gestão e o gerenciamento neste contexto. A partir disso, a pesquisa objetiva discutir a respeito da gestão de resíduos sólidos em territórios indígenas brasileiros. Como procedimentos metodológicos, adotou-se a pesquisa documental e análise de conteúdo. Os dados revelam que a diversidade cultural e ambiental dos povos indígenas nem sempre é levada em consideração no contexto da gestão de resíduos sólidos em seus territórios. Conclui-se que é dado maior atenção aos resíduos sólidos produzidos em centros urbanos do que àqueles produzidos em territórios indígenas, no entanto, ambos carecem de uma efetiva política sustentável de ocupação, uso e gestão dos diversos espaços.

Palavras-chave: Política pública; Legislação ambiental; Planos de gestão de resíduos sólidos.

\begin{abstract}
Reflections on the issue of solid waste in indigenous territories. The Brazilian National Solid Waste Policy presents respect for local and regional diversities as one of its guiding principles for integrated management throughout the Brazilian territory. It also points to the development of integrated management plans as an instrument for management and management in this context. Based on this, the research aims to discuss solid waste management in Brazilian indigenous territories. As methodological procedures, documental research and content analysis were adopted. The data reveal that the cultural and environmental diversity of indigenous peoples is not always taken into account in the context of solid waste management in their territories. It is concluded that more attention is given to solid waste produced in urban centers than to that produced in indigenous territories, however, both lack an
\end{abstract}

Recebido $04 / 06 / 2020$

Aceito

$23 / 11 / 2020$

Disponível on line $30 / 11 / 2020$

Publicado $31 / 12 / 2020$

Acesso aberto

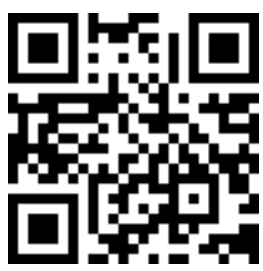

ORCID

(1) 0000-0001-6034-4057 Lucas Braga da Silva

(D) 0000-0001-7285-7423

Édi Augusto Benini

ISSN 2359-1412/RBGAS-2020-0091/2020/7/17/24/1425 
effective sustainable policy for the occupation, use and management of different spaces.

Keywords: Public policy; Environmental legislation; Solid waste management plans.

\section{Introdução}

A vida tradicional dos povos indígenas produz mais resíduos orgânicos do que de outros tipos, mas o contato com outras culturas e costumes contribuíram para que ocorressem modificações em seu estilo de vida. Assim, estas interações possibilitaram a assimilação de outras práticas como a de consumir materiais industrializados, tais como plásticos, tecidos, vidros, metais e outros (Gomes, 2013).

Com isso, percebe-se o aumento da quantidade de resíduos sólidos em domicílios indígenas e que em muitos casos a disposição destes ocorre diretamente na natureza. Em outros observa-se que o manejo dos resíduos ocorre de maneira inadequada. Isso pode ser decorrente da ausência de gestão e gerenciamento de resíduos, problema inédito para esta cultura. A carência deste tipo de procedimento resulta em consequências distintas para o modo de vida das sociedades indígenas e não indígenas (Higino, 2014; Lima, 2015).

Lima (2015, p.8) explica que a questão dos resíduos sólidos em territórios indígenas é uma questão pouco discutida em pesquisas científicas, uma vez que representa elevada importância para a sociedade, tanto com relação ao respeito a esses grupos repletos de diversidades e culturas, como com relação ao respeito pela natureza, pois, "apesar de serem sociedades difusas, cada vez mais sua contribuição na geração de resíduos vem aumentando".

Neste sentido, a Política Nacional de Resíduos Sólidos, dada pela Lei $\mathrm{n}^{0}$ 12.305/2010 (Brasil, 2010), reúne um conjunto de princípios, objetivos, instrumentos, diretrizes, metas e ações, que devem ser adotados isoladamente ou em parceria com agências governamentais e privadas, com vistas à gestão integrada e ao gerenciamento ambientalmente adequado de resíduos sólidos, bem como para viabilizar a gestão compartilhada pelo ciclo de vida dos produtos (Tavares e Athayde Júnior, 2014 Medeiros e Albuquerque, 2017).

Até o ano de 2012 esta política previa a elaboração de planos de gestão de resíduos sólidos (Jacobi e Besen, 2011; Maia et al., 2015) ao nível nacional, estadual, microrregional, intermunicipal, metropolitano e municipal (Brasil, 2010; Cezar, Barbosa e Reis, 2013). Desta forma, estes planos representam um avanço na questão dos resíduos sólidos, no sentido de apresentar alternativas de gestão e de gerenciamento, por meio de metas, programas e ações que viabilizem a sustentabilidade ambiental (Jacobi e Besen, 2011; Maia et al., 2015; Tavares e Athayde Júnior, 2014).

\section{Indígenas e a relação com a terra}

Viveiros de Castro (2017, p. 4) explica que "ser indígena é ter como referência primordial a relação com a terra em que nasceu ou onde se estabeleceu para fazer sua vida". É dela que os indígenas caçam, plantam e pescam (Kopenawa e Albert, 2015). Neste sentido, Levi-Strauss (1973, p. 325) mostra que os índios "concebem o local onde vivem como uma mãe, e não podem desfazer-se dele, nem trocá-lo". Nota-se que os indígenas possuem uma relação integrada, sistêmica e respeitosa pela natureza. Para eles é "proibido ferir sua mãe, a terra".

Albert (2002) faz alusão às consequências das práticas dos não indígenas para os indígenas. Ele cita que isto se deu, por exemplo, quando os homens brancos destruíram o lugar onde os povos Yanomami viviam. Kopenawa e Albert $(2015$, p. 27) reforçam tal 
problema ao descrever como um povo nativo foi sendo "engolido por uma máquina civilizacional incomensuravelmente mais poderosa". Albert (2002) destaca a competitividade centrada na dominação dos recursos naturais e de espaços designados para produção. Estas atividades impactaram negativamente no cotidiano dos indígenas Yanomami, pois estes estariam, em virtude disso, perdendo contato ou mesmo o domínio do seu território tradicional.

Os não indígenas que estão fortemente inseridos no modo capitalista de produção e distribuição, logo, preocupados prioritariamente em lucrar com o meio natural, tem dificuldades de equacionar devidamente as eventuais consequências de tal forma de desenvolvimento. Por isso exploram, destroem, desmatam e poluem para produzir cada vez mais riqueza monetária, muitas vezes sem pensar que essas ações podem ocasionar escassez dos insumos utilizados ou até a extinção de espécies e condenação de territórios, tornando várias extensões de terra inúteis mesmo para a agricultura moderna. Dessa forma, não possuem o mesmo respeito e cuidado com a terra que os povos originários. Ao invés de proceder com o devido cuidar, tais práticas tendem a causar muitas externalidades negativas sobre o ambiente, o que difere substancialmente do padrão de relacionamento que os indígenas trazem em suas práticas de sempre buscar proteger as diversidades naturais. A cosmologia ocidental capitalista objetifica a natureza, tratando-a como coisa a ser explorada, já as cosmologias indígenas tratam a natureza como sujeito, se relacionando com ela por meio de relações interpessoais e subjetivas (Albert, 2002).

Neste sentido, Albert (2002) apresenta a ecologia como um termo novo que veio como um discurso para a tomada de consciência dos não indígenas, que passam a se sensibilizar com a necessidade de pensar sobre a destruição da floresta e os inúmeros, e nocivos impactos disto. Kopenawa e Albert (2015, p. 481) apontam que "antes, a gente das cidades não se preocupava com a floresta. Nunca falavam nela e não temiam que ela pudesse ser destruída". Defendem que os povos não indígenas precisam ajudar os indígenas a "proteger o que ainda resta da floresta" (Kopenawa e Albert, 2015, p. 403), para estes autores não basta dizer que se defende a natureza sem atitudes concretas que comprovem tal ato.

Na visão de Kopenawa e Albert (2015, p. 476) os não indígenas "derrubam e queimam todas as árvores da mata para alimentar seu gado". Como se não bastasse, "estragam o leito dos rios e escavam os morros para procurar ouro". E "explodem as grandes pedras que ficam no caminho de suas estradas". Essas dentre tantas outras atitudes implicam em impactos negativos ao ecossistema e aos povos que habitam nele. Eles consideram que "a floresta está morta e vazia, que a natureza está aí sem motivo e que é muda".

A natureza para os não indígenas é visualizada somente para fins instrumentais e produtivos. Ela não é devidamente preservada, muito menos respeitada por aqueles que utilizam seus recursos. Se preocupam unicamente em atender aos requisitos de lucrabilidade do sistema econômico dominante. Estes são reconhecidos pelos indígenas como o povo da mercadoria e que mantém uma relação doentia com a terra. Para os indígenas a palavra meio ambiente é equivocada, pois representa o que restou da destruição desencadeada pelos não indígenas (Albert, 2002; Kopenawa e Albert, 2015).

Tradicionalmente, os povos indígenas retiram da natureza apenas o necessário para sua sobrevivência e de seu povo. É bastante respeitoso e equilibrado o relacionamento entre eles e ela. É no contato com ela que este povo constrói suas memórias. É um modo de vida sustentável e sem exploração daquilo que ela lhes proporciona. No momento em que pescam, executam a agricultura, caça, pesca e coleta de frutos evitam a agressão desnecessária (Albert, 2002; Kopenawa e Albert, 2015; Viveiros de Castro, 2017). 


\section{Indígenas e resíduos sólidos}

Para Marcondes (2014, p. 8) "a perda histórica das terras e dos recursos naturais e os constantes contatos interétnicos" trouxeram a "lógica econômica de mercado capitalista" ao cotidiano dos povos indígenas. Isto provoca certa dependência "das economias indígenas" por esta lógica, e, consequentemente, "alterado o padrão de consumo nas aldeias" e o volume de resíduos tende a aumentar no mesmo passo.

De acordo com Giatti et al. (2007) inexiste tratamento e destinação adequada para os resíduos sólidos em alguns territórios indígenas brasileiros, além de outros serviços essenciais, tais como água tratada, instalações sanitárias e rede de esgoto, que aliados à degradação ambiental, corroboram para danos ainda maiores à saúde destes povos.

A ausência de gestão e gerenciamento de resíduos sólidos adequada em áreas indígenas implica na queima destes e em outros destinos inadequados, como covas fechadas ou não, e, consequentemente, provoca problemas respiratórios, contaminação da água da referida comunidade e a incidência de outras problemáticas de saúde (Gonçalves Junior, 2017; Marcondes, 2014; Nogueira e Imperador, 2016).

A maior parte dos resíduos produzidos e enterrados em terras indígenas provém das regiões norte e centro-oeste. Além daqueles advindos em menor escala do sul e sudeste. Já a região nordeste apresenta importante participação dos sistemas de coleta oferecidos pelos serviços de limpeza. Ainda no nordeste é recorrente a questão de enterrar os resíduos (Gonçalves Junior, 2017).

Alguns integrantes dos territórios indígenas desconhecem os impactos ambientais e sociais gerados pela irregularidade do destino final, bem como alternativas para mitizar esse dano, como a coleta regular dos resíduos sólidos (Galdino et al., 2014; Nogueira e Imperador, 2016). Para Nogueira e Imperador (2016, p. 213) a educação e a informação ambiental que retrate adequadamente os principais aspectos dessa questão podem se constituir em ferramentas importantes "na mudança de conceito e, consequentemente, de comportamento" destas comunidades.

Contudo, é significativo assinalar que, as atividades econômicas tradicionais desenvolvidas por povos indígenas em seus respectivos territórios consideram "o conhecimento e respeito à natureza, as tradições, crenças e visões destes povos sobre o mundo". A interconexão entre natureza e estes povos são vistas como primordiais para o desenvolvimento de atividades deste tipo (Marcondes, 2014, p. 34).

Porém, ao incorporar gradativamente aspectos, especialmente do modo de consumo, dos não indígenas, os indígenas se param com uma nova realidade e problemáticas inédita nas suas práticas. Não por acaso, aspectos de gestão e gerenciamento de resíduos sólidos em aldeias indígenas diz respeito a um assunto pouco debatido, mas importante e que carece cada vez de mais atenção. A intenção de incluir essa nova abordagem - gestão de resíduos sólidos nas comunidades indígenas - é de que seja garantido aos indígenas por meio destas atividades a permanência da integridade de seu patrimônio e do respeito as peculiaridades etnoculturais. Além da qualidade de vida e saúde (Higino, 2014; Lima, 2015).

A política de resíduos sólidos apresenta justamente o respeito as diversidades locais e regionais como um princípio orientador de gestão e gerenciamento neste contexto (Brasil, 2010; Medeiros e Albuquerque, 2017). Meneses (2012) explica que a sustentabilidade já está inserida nos aspectos culturais e nas realidades dos povos tradicionais e de outras localidades, e destaca que a cultura está integrada com a natureza e que não há como dissociar uma da outra.

No entanto, essa política define que os resíduos são produzidos a partir das atividades realizadas em domicílios, na limpeza urbana, em empresas públicas e privadas, na indústria, na construção civil, na agropecuária, na silvicultura, no transporte de cargas e/ou pessoas, na mineração e devido à periculosidade (Brasil, 2010), logo, percebe-se que não há referência a resíduos produzidos em territórios indígenas. É destacado no Plano 
Nacional de Resíduos Sólidos duas estratégias para esta problemática em territórios indígenas: o desenvolvimento de políticas públicas e a necessidade de gestores capacitados tecnicamente e recursos financeiros adequados (MMA, 2012).

As ameaças de insustentabilidade ambiental atingem tudo e todas as formas de vida presentes em determinada localidade. A questão determinante na sustentabilidade efetiva da vida está nas relações em que cada grupo ou povo estabelece com o meio ambiente. A identidade constituída neste contexto pode revelar diversas maneiras de lidar com esta realidade (Meneses, 2012).

\section{Resíduos sólidos e instrumentos de gestão}

Os resíduos sólidos podem ser definidos como todo e qualquer tipo de matéria sólida ou semissólida descartada e que é resultante dos processos de produção e consumo da sociedade (Brasil, 2010). Reconhece-se, entretanto que, os resíduos produzidos, não coletados ou dispostos de modo irregular, tendem, a gerar efeitos negativos para o meio ambiente e para a saúde pública (Jacobi e Besen, 2011; Jacobi et al., 2014; Tavares e Athayde Júnior, 2014; Maia et al., 2015).

Assim, a gestão integrada pode ser vista como uma alternativa sustentável para os resíduos sólidos (Brasil, 2010), a qual deve considerar a promoção de um conjunto de comportamentos e procedimentos necessários para minimizar os impactos ambientais negativos da produção e consumo de produtos (Cortez, 2016), de modo a considerar aspectos políticos, econômicos, ambientais, culturais e sociais (Medeiros e Albuquerque, 2017), com a garantia de informações e participação nos processos de políticas públicas (Cezar, Barbosa e Reis, 2013; Klein et al., 2018; Pires e Gomide, 2016) e atendimento as premissas de desenvolvimento sustentável (Cortez, 2016; Klein et al., 2018; Medeiros e Albuquerque, 2017).

Neste interim, "a administração pública municipal tem a responsabilidade de gerenciar os resíduos sólidos, desde a sua coleta até a sua disposição final, que deve ser ambientalmente segura" (Jacobi e Besen, 2011, p. 136).

Brasil (2010) explica que a Política Nacional de Resíduos Sólidos integra a Política Nacional do Meio Ambiente, articulando-se, especialmente, com a Política Nacional de Educação Ambiental, regulada pela Lei no 9.795/1999 (Brasil, 1999), com a Política Federal de Saneamento Básico, regulada pela Lei no 11.445/2007 (Brasil, 2007), e com a Lei no 11.107/2005 (Brasil, 2005), que trata dos consórcios públicos (Maia et al., 2015).

Medeiros e Albuquerque (2017) reiteram que a política de resíduos sólidos apresenta instrumentos de gestão e gerenciamento para auxiliar no enfrentamento das problemáticas ambientais, sociais e econômicas vivenciadas pelos estados e municípios brasileiros decorrentes da disposição e destinação inadequada dos resíduos, dentre as quais, a educação ambiental, os planos de gestão e gerenciamento, a coleta seletiva e a logística reversa.

Há, ainda, outras questões evidenciadas pela política, a saber, a necessidade de estabelecer programas e ações de educação ambiental que promovam a não produção, a redução, a reutilização e a reciclagem dos materiais consumidos, estimular a prática de consumo sustentável, priorizar as compras sustentáveis, articulação entre os atores internos e externos ao estado e o desenvolvimento de sistemas de gestão empresarial pautados na sustentabilidade (Brasil, 2010).

Pires e Gomide (2016, p. 128) consideram a articulação com instituições governamentais, nos estados e municípios, e com agentes externos ao governo como um mecanismo de gestão que possibilita ampliar os resultados de políticas públicas ambientais, sociais, econômicas, dentre outras. Portanto, "isso amplia a aquisição de informações sobre os problemas, aumenta o estoque de conhecimento disponível para a formulação das soluções" neste sentido (Pires e Gomide, 2016, p. 126). 
Tavares e Athayde Júnior (2014, p. 39) acrescentam que os planos de resíduos sólidos em âmbitos nacional, estadual e municipal, devem conter, entre outras diretrizes, a identificação dos fluxos de resíduos sólidos, indicação de possíveis soluções para esta questão e a maneira adotada para a sua disposição final. Outras questões como "metas gradativas de redução, reutilização e reciclagem, com o objetivo de reduzir a quantidade de resíduos e rejeitos encaminhados para disposição no solo" devem ser consideradas com mais especificidade pelos planos dos municípios (Jacobi e Besen, 2011, p. 139).

Quanto à logística reversa, convém asseverar, é uma estratégia da logística empresarial, que busca o conserto, descarte adequado ou a reintegração de materiais ao mercado pelos respectivos produtores. Assim, a logística reversa apresenta alternativas de gestão sustentável para aqueles resíduos sólidos considerados danificados ou inoperantes pelos consumidores e pelas empresas (Guarnieri, 2011; Tavares e Athayde Júnior, 2014; Cortez, 2016).

Entre os estudiosos, alguns entendem que a coleta seletiva, dentre outras questões, pode ser vista como uma solução sustentável para os resíduos sólidos, uma vez que seus reflexos podem minimizar os danos negativos à saúde pública e ao ambiente (Besen et al., 2014; Cortez, 2016; Jacobi e Besen, 2011), devido a sua capacidade de coletar resíduos sólidos previamente separados de acordo com a sua constituição ou composição. Contudo, é necessário o estímulo e o fortalecimento desta prática com a integração de catadores de materiais recicláveis (Brasil, 2010).

Outrossim, é significativo acrescentar, a responsabilidade compartilhada pelo ciclo de vida dos produtos consumidos como um meio para reduzir o volume de resíduos produzidos e minimizar os impactos à saúde e ao ecossistema. Para tal, a responsabilidade se estende tanto a fabricantes, importadores, distribuidores, comerciantes, sociedade quanto de titulares de serviços de limpeza urbana e manejo dos resíduos (Brasil, 2010; Cortez, 2016).

Neste contexto, convém frisar, que a educação ambiental é, de certa forma, um mecanismo que auxilia positivamente na implementação da política de resíduos sólidos, especialmente, a gestão integrada e sustentável de resíduos sólidos, uma vez que este tipo de educação está pautado na formação de cidadãos preocupados com a sustentabilidade ambiental e que busque alternativas para a conservação e preservação dos recursos naturais (Maia et al., 2015).

Assim, a presente pesquisa tem como objetivo analisar os planos de gestão de resíduos sólidos elaborados pelos estados do Brasil, no sentido de compreender de que maneira as questões relativas aos resíduos sólidos em territórios indígenas são tratadas.

\section{Material e métodos}

A coleta de dados constituiu-se a partir de pesquisa documental nos planos de gestão de resíduos sólidos dos estados brasileiros. Para tanto, foram consideradas informações inerentes aos resíduos sólidos em territórios indígenas disponíveis nestes planos. Para melhor justificar a pesquisa, convém esclarecer que apesar da gestão de resíduos sólidos ser competência dos municípios, para esta análise, considerou-se como objeto o conteúdo disposto pelos planos, porque estes apresentam (ou deveriam apresentar) uma visão dos fluxos de resíduos sólidos e de alternativas de gestão para áreas indígenas e outras.

Para a identificação do corpus de análise, consultaram-se os sites das secretarias estaduais com competência para a gestão de resíduos sólidos. Os documentos foram encontrados por meio de buscas realizadas no respectivo site utilizando os seguintes descritores: plano estadual de resíduos sólidos ou resíduos sólidos.

O critério de seleção do corpus de análise foi a elaboração dos respectivos planos até 20 de maio de 2020. Desta forma, os Estados do Acre, Alagoas, Amazonas, Ceará, 
Distrito Federal, Espírito Santo, Goiás, Maranhão, Mato Grosso do Sul, Pará, Paraíba, Paraná, Pernambuco, Rio de Janeiro, Rio Grande do Norte, Rio Grande do Sul, Santa Catarina, São Paulo, Sergipe e Tocantins adequaram-se a este critério.

A pesquisa adotou a análise do conteúdo dos documentos que é "uma técnica para o tratamento de dados que visa a identificar o que está sendo dito a respeito de determinado tema" (Vergara, 2008, p. 15), consistindo nas etapas de pré-análise, exploração do material e tratamento dos resultados (Bardin, 1977).

\section{Resultados e discussão}

\section{Mobilização social}

Em relação à mobilização social com vistas a atingir os objetivos dos planos de resíduos de acesso à informação, nota-se que os Estados do Acre e Alagoas consideraram ferramentas de comunicação específicas para alcançar os diferentes grupos-alvo, incluindo os indígenas. Ramesh et al. (2016, p. 13) pontuam que é propício o desenvolvimento de estruturas e processos de comunicação que possibilitem a troca de informações de duas vias entre o Estado e os cidadãos, uma vez que é difícil para os estados responderem às necessidades e expectativas do público sem estes processos e estruturas.

A mobilização social de atores estatais e não estatais é uma ferramenta importante na elaboração, implementação e avaliação de políticas públicas. Para tanto, é preciso um conjunto de mecanismos de comunicação que produzam e disponibilizem aos grupos de interesse um conteúdo claro, sem ruídos e distorções. No entanto, esta pesquisa aponta que a maior parte dos estados (18) não demonstraram preocupação em motivar os indígenas a participarem das discussões decisórias relativas aos resíduos sólidos.

Dada à situação de atraso crônico e negligência histórica em que a gestão e o gerenciamento de resíduos sólidos se encontra no Brasil, a mobilização de atores sociais para as arenas de debates públicos pode ser vista como uma alternativa para auxiliar no enfrentamento deste tema (Rolnik, 2012).

\section{Dados e informações}

Outra questão verificada é a ausência de dados e informações a respeito da produção de resíduos nas terras indígenas do Acre. Conforme apontam alguns autores, esta questão é um desafio até mesmo para áreas urbanas brasileiras, a exemplo aquelas localizadas na Bacia hidrográfica do Alto Tietê (Klein et al., 2018) e em São Paulo (Jacobi e Besen, 2011). Embora apenas um estado tenha se manifestado com relação à esta dificuldade, é possível que outros passem por esse mesmo problema, mas não se manifestaram. Contudo, é relevante destacar que quando se trata de resíduos sólidos existe uma carência neste sentido e que por vezes impossibilita uma análise mais detalhada da questão nas localidades brasileiras (Jacobi e Besen, 2011; Cezar et al., 2013; Klein et al., 2018). Porém, o acesso e a disponibilidade de informações são processos que precisam se fortalecer na questão dos resíduos sólidos, tendo em vista que representam um fator importante para a participação da sociedade na gestão de políticas públicas (Klein et al., 2018).

\section{Participação social}

Com relação à participação social, percebe-se atenção especial de alguns estados (Acre, Alagoas e Maranhão) em incluir a sociedade civil, agências governamentais, instituições do terceiro setor e empresas privadas, especialmente os indígenas, nas arenas de discussões sobre resíduos sólidos e os seus processos de gestão. Pires e Gomide (2016) complementam que as interações com diferentes grupos sociais e os canais de participação social, tendem a ampliar, relativamente, os resultados das políticas públicas. 
Assim, é nítido que os planos da maioria dos estados estudados (17) não fizeram referência a participação de indígenas na gestão de resíduos.

\section{Situação dos resíduos sólidos}

A análise dos dados revela que durante a elaboração do plano do Amazonas houve levantamento e mapeamento dos principais geradores de resíduos, com o intuito de mensurar o volume, observar a origem, conhecer as características e os tipos de coleta e maneiras de destinação e disposição adotada, considerando, ainda, a condição dos resíduos passíveis de logística reversa, dos materiais coletados pelos catadores e dos fluxos de resíduos em geral neste estado, incluindo os territórios indígenas. No plano de Alagoas um dos pontos de destaque é a organização de processos para elaboração do inventário de resíduos sólidos nas terras indígenas. Deste modo, é possível perceber que estes estados se preocuparam em atender as determinações da política de resíduos sólidos, especialmente, os requisitos mínimos dos planos, a saber, diagnóstico da situação dos resíduos sólidos e a proposição de alternativas sustentáveis para esta questão (Brasil, 2010). Em contrapartida, outros 18 planos não expuseram nada a respeito da situação dos resíduos nas terras indígenas em seu território. Isto representa um prejuízo para os povos indígenas porque a sua realidade e contexto não foram considerados.

\section{Manejo de resíduos sólidos}

Outro ponto destacado e que representa uma dificuldade é a inexistência de sistemas de coleta e destinação de resíduos sólidos em diversos territórios indígenas no Acre. Os resíduos são depositados em locais próximos destes territórios e sem nenhum controle, o que pode prejudicar a saúde e o ambiente. Giatti et al. (2007) encontraram as mesmas dificuldades quando desenvolveram pesquisa no Distrito Indígena Iauretê, Amazonas. Para resolver esta questão, o Acre apresenta como alternativa a utilização de novas tecnologias e processos que consideram a geração de resíduos sólidos, as centrais de recebimento e armazenamento, polos de estocagem, disposição final de rejeitos e recuperação de recursos. Um outro plano (Paraná) reitera a importância de tecnologias sociais na gestão e gerenciamento de resíduos sólidos nestes espaços. Klein et al. (2018, p. 150) ratificam que "o uso de inovações e mecanismos tecnológicos" contribuem "para minimizar os impactos ambientais e sociais negativos" dos resíduos sólidos.

Em outros estados (Espírito Santo, Mato Grosso do Sul, Pará e Rio Grande do Sul) a coleta de resíduos nestes territórios é apresentado como uma estratégia de gestão que deve ser desenvolvida. Um outro estado (Mato Grosso do Sul) trata da elaboração de um projeto para a criação de unidades de triagem de resíduos sólidos, unidades de compostagem e de transbordo de resíduos sólidos e como conteúdo mínimo é exigido a inclusão dos povos e territórios indígenas. Apesar das dificuldades do Acre com relação ao manejo de resíduos sólidos, nota-se certa preocupação com esta questão em seus territórios indígenas. Por fim, o estado da Paraíba refere-se a coleta regular nestas comunidades. De acordo com Galdino et al. (2014) a presença de resíduos sólidos de variados tipos no ambiente natural dos indígenas pode comprometer a preservação do seu patrimônio material e imaterial. Posto isso, é perceptível que a grande maioria dos estados (13) não tiveram o cuidado de destacar a questão do manejo de resíduos nestas localidades.

\section{Coleta seletiva}

Cabe destacar que dois dos planos (Amazonas e Espírito Santo) apresentam um diferencial em relação aos demais, uma vez que apontam o incentivo a implantação e ampliação da cobertura dos serviços de coleta seletiva de resíduos sólidos nestas comunidades. Besen et al. (2014) evidenciaram em seu estudo na região de São Paulo que a coleta seletiva possibilita a utilização de menos recursos da natureza e minimização da 
geração de resíduos sólidos. A coleta seletiva representa uma solução sustentável inovadora para os resíduos em terras indígenas, uma vez que por meio da separação de acordo a sua composição, em momentos posteriores a coleta, é possível a reciclagem e outros processos de reaproveitamento. Para tanto, é conveniente o investimento em educação ambiental, destacando a importância desta atividade e os impactos gerados pela destinação incorreta de resíduos. Poucos estados defenderam o uso desta ferramenta em territórios indígenas, um total de 2 , os 18 restantes não desenvolveram conteúdo algum neste sentido.

\section{Logística reversa}

Os dados mostram que os estados do Acre e Amazonas apresentaram propostas com relação à criação dos fluxos de criação dos fluxos de retorno e concentração/estocagem de materiais recicláveis e aqueles sujeitos à logística reversa em aldeias indígenas. Guarnieri (2011) e Cortez (2016) consideram que os fluxos de logística reversa instituídos na gestão de resíduos sólidos contribuem para a maximização dos fluxos de reciclagem e reutilização de embalagens. Apesar da logística reversa constituir um mecanismo relevante para o retorno de resíduos ao setor produtivo, nota-se que a maioria dos planos estaduais estudados (18) não consideraram esta possibilidade nestes indígenas.

\section{Educação ambiental}

Araujo et al. (2019) explicam que arquitetar programas educativos, de conscientização e de disseminação de informações na área ambiental no interior das comunidades, pode contribuir para que o respeito e a valorização do patrimônio natural e cultural seja realidade em determinado contexto. Assim, é significativo destacar que os estados do Acre e Amazonas apresentaram como diretiva a educação ambiental sobre o manejo dos resíduos sólidos para as populações indígenas. Pela análise dos dados, nota-se pouca notoriedade da educação ambiental com vistas a questão dos resíduos, uma vez que dos 20 planos estudados, apenas dois deles demonstraram alguma preocupação. Contudo, é significativo ressaltar que, a educação ambiental é um fator que contribui para que a coleta seletiva e a logística reversa sejam colocadas em prática.

\section{Consórcios públicos}

Um dos estados brasileiros (Amazonas) apresenta os consórcios públicos como alternativa para o enfrentamento desta problemática em áreas indígenas. Jacobi e Besen (2011) identificaram em sua pesquisa que a adoção de consórcios públicos contribui para ampliar a capacidade de gestão de resíduos sólidos, reduzir custos e propiciar tratamento e destinação adequados. Nota-se, portanto, que este mecanismo é pouco abordado pelos planos, uma vez que somente um dos 20 retrataram algo sobre isto. Porém, é um mecanismo que carece de mais atenção quanto a sua adoção ou outras maneiras de cooperação entre os entes federados. É oportuno pensar maneiras de executar a gestão consorciada de resíduos nestes espaços.

\section{Programas e ações governamentais}

Outra questão levantada é o desenvolvimento de programas e ações governamentais voltados para a gestão de resíduos sólidos em territórios indígenas. 0 Acre apresenta como meta a capacitação e a informação nestes territórios. No Amazonas, os programas, projetos e ações, devem observar os seguintes critérios: a estruturação da gestão e gerenciamento de resíduos sólidos neste estado, a implementação de coleta seletiva, educação ambiental, fiscalização, destinação e disposição adequada nas áreas indígenas. 
No Rio Grande do Sul é visto as seguintes estratégias arquitetadas: fomentar os serviços de limpeza pública, a coleta e destinação final em territórios indígenas de modo diferenciado e de acordo com especificidades tradicionais deste estado. Um dos destaques elencados pelos planos dos estados do Mato Grosso do Sul e do Paraná é a assistência técnica e financeira no desenvolvimento de ações de gestão integrada de resíduos sólidos nas comunidades indígenas. Já no Tocantins é apontado a oferta de recursos para o desenvolvimento de projetos ambientais nos territórios indígenas por meio da Coordenadoria Ecumênica de Serviço (CESE).

Neste sentido, Lima (2015) destaca que implementar programas e ações desse tipo nestes territórios são importantes para possibilitar alternativas ambientalmente adequadas para o lixo produzido e reduzir riscos à saúde. De modo geral, seis dos 18 planos de resíduos analisados apresentaram algum tipo programa/ação com o intuito de evidenciar a questão dos resíduos sólidos.

\section{Respeitos às diversidades culturais e patrimoniais}

Um avanço nesta questão é o respeito às tradições, aos hábitos e aos costumes indígenas. No entanto, isto só é possível por meio do manejo adequado dos resíduos sólidos. Os estados de Acre, Amazonas, Espírito Santo, Paraná, Rio Grande do Sul conseguiram avançar neste sentido. Os 15 restantes, não evidenciaram nada a este respeito. 0 Acre, por exemplo, possui um guia para a gestão e o manejo de resíduos sólidos em aldeias indígenas. Neste sentido, é importante destacar o interesse dos estados do Espírito Santo, Paraná e do Rio Grande do Sul com relação ao desenvolvimento e implementação de políticas públicas para a gestão de resíduos sólidos. Assim, Araujo et al. (2019) consideram a criação e implementação de projetos e políticas públicas como necessárias para a proteção do patrimônio ambiental e cultural destes e de outros territórios.

Os povos indígenas são repletos de especificidades ligadas a cultura, ao respeito ao meio ambiente, entre outros aspectos, mas o que é bastante nítido é que eles possuem uma maneira diferente de tratar a terra dos não indígenas. Contudo, é preciso pensar sobre os impactos gerados pelos resíduos sólidos neste modo de vida tradicional, bem como estratégias de gestão para minimizar as problemáticas advindas do contato destes povos com materiais industrializados.

Dados do diagnóstico da gestão de resíduos sólidos dos estados de Goiás, Mato Grosso do Sul, Rio Grande do Sul e Tocantins definiram como uma diretiva a exclusão dos territórios indígenas destes estados de áreas potenciais para a destinação e disposição de resíduos sólidos. Os 16 restantes, não evidenciaram nada neste sentido. Porém, isto é, de certo modo, uma maneira de respeito a estes territórios e aos povos que nele vivem, pois existe a preocupação de não depositar resíduos nestes espaços. 0 que deve ficar claro é que não foi explicitado nenhuma diretriz específica com relação ao respeito aos aspectos culturais e patrimoniais dos indígenas. Para tanto, é apropriado quando da definição dos métodos e procedimentos específicos de gestão e gerenciamento de resíduos sólidos em territórios indígenas, ponderar os hábitos e valores de comunidades tradicionais, os tipos de resíduos produzidos e o contexto em que estas comunidades estão inseridas (Medeiros e Albuquerque, 2017).

\section{Outras questões evidenciadas}

Por meio da análise realizada, é possível perceber que um dos estados estudados (Pernambuco) faz referência somente a representatividade do artesanato indígena para a região, outros sete (Ceará, Distrito Federal, Rio de Janeiro, Rio Grande do Norte, Santa Catarina, São Paulo e Sergipe) não existe alguma menção sobre estratégias de gestão para os resíduos sólidos em terras indígenas. Nota-se, portanto, conforme as pesquisas de 
Galdino et al. (2014) e de Higino (2014), que nem sempre esta questão é abordada pelas diretrizes e metas governamentais.

Uma questão evidenciada pela análise de um dos planos (Pará) é que os territórios indígenas são de responsabilidade da administração federal e por isso é preciso pensar na possibilidade de exclusão da obrigatoriedade da gestão de resíduos sólidos dos municípios, uma vez que estes últimos perpassam por dificuldades financeiras e de infraestrutura. Para tanto, esta temática pode ser inserida na meta de arquitetar estratégias para minimizar os danos gerados pela contaminação por resíduos, disposto pela Política Nacional de Gestão Territorial e Ambiental de Terras Indígenas. Porém, este mesmo estado reconhece a necessidade de procedimentos de gestão e gerenciamento de resíduos nestas terras para minimizar os problemas sociais gerados pela disposição inadequada destes.

Contudo, é significativo assinalar, os textos que tratam de resíduos sólidos, a saber, Política Nacional, Plano Nacional e Planos estaduais de resíduos sólidos pouco apresentam metas e ações voltadas aos territórios indígenas. Em se tratando dos estados, alguns deles nem fazem referência ao respeito às diversidades culturais e territoriais dos povos indígenas e apresentam dados relacionados a geração e destinação de resíduos nestes territórios.

\section{Considerações finais}

Esta pesquisa trouxe uma análise dos planos de gestão de resíduos sólidos de estados do Brasil, com o intuito compreender de que maneira as questões relativas aos resíduos sólidos em territórios indígenas são tratadas.

Observamos então que as políticas públicas para a gestão de resíduos sólidos em territórios indígenas ainda estão em uma fase preliminar de elaboração e implementação. Aqui há um conjunto de desafios que perpassam essa questão, que em essência, trata-se de preservar as dinâmicas sustentáveis que os territórios indígenas já tinham, e que agora estão em risco.

A Política Nacional de Resíduos Sólidos demonstra maior representatividade dos resíduos sólidos gerados pela sociedade não indígena e indústrias. As comunidades indígenas aparecem de modo bastante tímido nos textos deste instrumento de gestão e gerenciamento de resíduos sólidos.

Apenas alguns estados brasileiros apresentaram conteúdos mais específicos a respeito da realidade dos resíduos sólidos em territórios indígenas. Poucos preencheram os espaços vazios das páginas em branco com textos que retratam especificidades da coleta seletiva e logística reversa nestes espaços. Outras questões também pouco foram representadas, a saber, educação ambiental, consórcios públicos.

A referida política é realidade para o território brasileiro desde 2010. Isto representa um avanço na gestão e gerenciamento de resíduos sólidos no Brasil. Por outro lado, nota-se pouca atenção aos aspectos culturais e ambientais dos povos indígenas, ausência de dados relacionados a problemas de saúde causado pelos resíduos depositados de modo inadequado no ambiente, acesso à informação e transparência pública ruim neste sentido e, até mesmo descaso por parte da administração pública.

Ainda é preciso incluir atores diversificados (indígenas e outros povos) nos textos, discussões e decisões públicas. Assim, a realidade de determinado povo, localidade pode ser representada de maneira a considerar todas as especificidades vivenciadas neste contexto. Contudo, é importante destacar poucas referências sobre processos de mobilização e participação social. 0 respeito a diversidade cultural deve ser considerado em todos os aspectos do ciclo de uma política pública.

Desta forma, o desafio é evitar que os territórios indígenas, que já trazem na essência e nas práticas da sua cultura a sustentabilidade, retroceder na medida em que

Rev. Bras. Gest. Amb. Sustent., 2020, vol. 7, n. 17, p. 1425-1438. 
inserem ou se aproximam do desenvolvimento dos não indígenas. Para isso, é preciso pensar em alternativas para os resíduos sólidos trazidos pelo desenvolvimento moderno e maneiras de preservação da cultura indígena com relação ao ambiente.

Para um próximo estudo, a sugestão que fica é de que seja realizada uma análise da gestão de resíduos sólidos sob a perspectiva da administração municipal; esfera de governo responsável pela gestão de resíduos, mas que também realize uma análise documental dos respectivos planos municipais dos estados brasileiros.

\section{Conflito de interesses}

Os autores declaram não haver conflito de interesses.

\section{Referências}

Albert, B. O ouro canibal e a queda do céu: uma crítica xamânica da economia política da natureza (Yanomami). In: Ramos, A.; Albert, B. Pacificando o branco: cosmologias do contato do norte amazônico. São Paulo: UNESP, 2002.

Araujo, M. P.; Bem, J. S.; Waismann, M. Patrimônio natural e cultural: breves considerações sobre a tutela do Estado. In: Calgaro, C.; Brasil, D. R; Gomes, M. F. (Orgs.). Poder de polícia, desenvolvimento sustentável e socioambientalismo. Porto Alegre: Fi, 2017. p. 139-154.

Bardin, L. Análise de conteúdo. Lisboa: Edições 70, 1977.

Besen, G. R.; Ribeiro, H.; Günther, W. M. R.; Jacobi, P. R. Ambiente \& Sociedade, v. 17, n. 3, p. 259-278, 2014. https://doi.org/10.1590/S1414-753X2014000300015

Brasil. Lei no 12.305, de 2 de agosto de 2010. Institui a Política Nacional de Resíduos Sólidos; altera a Lei $\mathrm{n}^{-}$9.605, de 12 de fevereiro de 1998; e dá outras providências. Disponível em: <http://www.planalto.gov.br/ccivil_03/_ato2007-2010/2010/lei/ 112305.htm>. Acesso em: 22 maio 2018.

Cezar, L. C.; Barbosa, T. R. C. G.; Reis, M. C. T. Interfaces da comunicação pública e governamental na divulgação da política nacional dos resíduos sólidos. Revista de Ciências Humanas, v. 13, n. 1, p. 102-120, 2013.

Cortez, A. T. C. Aplicação de métodos e técnicas sustentáveis na gestão de resíduos sólidos. GeoGraphos, v. 7, n. 87, p. 1-27, 2016.

Galdino, L. K. A.; Silva, E. V.; Falcão, M. T.; Pinheiro, M. N. M.; Oliveira, S. K. S. A questão indígena em Roraima: análise socioambiental na comunidade indígena Boca da Mata na Terra Indígena São Marcos. Revista Eletrônica Ambiente: Gestão e Desenvolvimento, v. 6, n. 1, p. 81-88, 2014. https://doi.org/10.24979/225

Giatti, L. L.; Rocha, A. A.; Toledo, R. F.; Barreira, L. P.; Rios, L.; Pelicioni, M. C. F.; Mutti, L. V.; Cutolo, S. A. Condições sanitárias e socioambientais em Iauaretê, área indígena em São Gabriel da Cachoeira, AM. Ciência \& Saúde Coletiva, v. 12, n. 6, p. 1711-1723, 2007. https://doi.org/10.1590/S1413-81232007000600032

Gomes, S. L. Resíduos sólidos dos serviços de saúde em terras indígenas: o caso do distrito sanitário especial indígena médio Rio Purus, Amazonas. Brasília: Universidade de Brasília, Brasília, 2014. (Dissertação de mestrado).

Gonçalves Junior, A. G. 0 direito sanitário na sociedade de risco: a política nacional de atenção à saúde dos Povos Indígenas. Porto Alegre: Fi, 2017. 
Guarnieri, P. Logística reversa: em busca do equilíbrio econômico e ambiental. Recife: Clube de Autores, 2011.

Higino, C. B. C. Proposta de instalação de sistema de gerenciamento de resíduos sólidos da aldeia fulni-ô. Rio de Janeiro: Universidade Federal do Rio de Janeiro, 2014. (Dissertação de mestrado).

Jacobi, P. R.; Besen, G. R. Gestão de resíduos sólidos em São Paulo: desafios da sustentabilidade. Estudos Avançados, v. 25, n. 71, p. 135-158, 2011. https://doi.org/ 10.1590/S0103-40142011000100010

Klein, F. B.; Gonçalves-Dias, S. L. F.; Jayo, M. Gestão de resíduos sólidos urbanos nos municípios da Bacia Hidrográfica do Alto Tietê: uma análise sobre o uso de TIC no acesso à informação governamental. Revista Brasileira de Gestão Urbana, v. 10, n. 1, p. 140-153, 2018. https://doi.org/10.1590/2175-3369.010.001.ao10

Kopenawa, D.; Albert, B. A queda do céu: palavras de um Xamã Yanomami. São Paulo: Companhia das Letras, 2015.

Levi-Strauss, C. Antropologia estrutural II. Rio de Janeiro: Tempo Brasileiro, 1993.

Lima, R. O. Gestão de resíduos sólidos em aldeias indígenas: estudo de caso do Distrito Sanitário Especial Indígena Ceará. Fortaleza: Universidade Federal do Ceará, 2015. (Dissertação de mestrado).

Maia. H. J. L.; Freitas, J. P.; Alencar, L. D.; Cavalcante, L. P. S.; Barbosa, E. M. Legislação ambiental da Paraíba: contribuições à gestão integrada de resíduos sólidos. Revista Monografias Ambientais, v. 14, n. 1, p. 14-19, 2015.

Marcondes, C. Descarte do lixo e seu impacto no ambiente e saúde: percepção das comunidades indígenas de Mangueirinha-PR. Pato Branco: Universidade Tecnológica Federal do Paraná, 2014. (Dissertação de mestrado).

Medeiros, F. L. F.; Albuquerque, L. A Política Nacional de Resíduos Sólidos e o desenvolvimento sustentável. In: Bühring, M. A.; Medeiros, F. L. F. (Orgs.). Reflexões sobre direito ambiental e sustentabilidade. Porto Alegre: Fi, 2017. p. 28-45.

Meneses, V. D. Meio ambiente e televisão: um perfil da Programação Regional Aberta no Brasil. Comunicação \& Sociedade, v. 34, v. 1, p. 57-81, 2012. https://doi.org/10.15603/ 2175-7755/cs.v34n1p57-81

MMA - Ministério do Meio Ambiente. Plano Nacional de Resíduos Sólidos do Brasil. Brasília: Ministério do Meio Ambiente, 2012.

Nogueira, A. C. C.; Imperador, A. M. Diagnóstico ambiental através do uso da metodologia participativa: estudo de caso da aldeia indígena Xucuru-Kariri. Gesta, v. 4, n. 2, p. 207-219, 2016. https://doi.org/10.9771/gesta.v4i2.14280

Pires, R. R. C.; Gomide, A. A. Governança e capacidades estatais: uma análise comparativa de programas federais. Revista de Sociologia e Política, v. 24, n. 58, p. 121-143, 2016. https://doi.org/10.1590/1678-987316245806

Ramesh, M.; Saguin, K.; Howlett, M. P.; Xun, W. Rethinking governance capacity as organizational and systemic resources. Lee Kuan Yew School of Public Policy Research Paper, n. 16-12, p. 1-32, 2016. https://doi.org/10.2139/ssrn.2802438

Rolnik, R. Resíduos sólidos urbanos: repensando suas dimensões. In: Santos, M. C. L.; Dias, S. L. F. G. (Orgs.). Resíduos sólidos urbanos e seus impactos socioambientais. São Paulo: IEE-USP, 2012. 
Tavares, P. T.; Athayde Júnior, G. B. Disposição final dos resíduos sólidos em 90 municípios paraibanos: análise da condição atual frente às exigências da Política Nacional de resíduos sólidos. Gesta, v. 2, n. 1, p. 38-52, 2014. https://doi.org/10.17565/gesta.v2i1.8772

Vergara, S. C. Métodos de pesquisa em administração. 3 ed. São Paulo: Atlas, 2008.

Viveiros de Castro, E. Os involuntários da pátria: elogio do subdesenvolvimento. Revista Chão de Feira, Série Intempestiva, n. 65, p.1-9, 2017. Disponível em: $<$ https://chaodafeira.com/wpcontent/uploads/2017/05/SI_cad65_eduardoviveiros_ok.p df>. Acesso em: 25 nov. 2018. 